\title{
VISCOSITY OF METHANE-CHLORODIFLUOROMETHANE (R22) GASEOUS MIXTURES IN THE TEMPERATURE RANGE FROM 298.15 TO 373.15 K AND AT PRESSURES UP TO $5 \mathrm{MPa}$
}

\author{
Masaru HONGO \\ College of Industrial Technology, Nihon University, Narashino 275 \\ CHIAKI YOKOYAMA AND SHINJI TAKAHASHI \\ Chemical Research Institute of Non-Aqueous Solutions, \\ Tohoku University, Sendai 980
}

Key Words: Physical Property, High Pressure, Viscosity, Gas Mixture, Correlation, Methane, Chlorodifluoromethane

\begin{abstract}
The gas-phase viscosity of the methane-chlorodifluoromethane (R22) system was measured in the temperature range from 298.15 to $373.15 \mathrm{~K}$ and at pressures up to $5 \mathrm{MPa}$. The measurements were performed with a Maxwell type oscillating-disc viscometer. The viscosity at atmospheric pressure was correlated by three methods: the Chapman-Enskog equation, the Sutherland equation with Wilke combination factors and the Sutherland equation with Brokaw factors. It was found that the results calculated from the Sutherland equation with Brokaw combination factors gave the best agreement with the experimental data. The viscosity data at various pressures could not be correlated successfully by the residual viscosity correlations of Dean and Stiel or the equation of Pedersen et al. A new empirical equation for the correlation factor was proposed that extends the corresponding states viscosity equation with methane as the reference substance to the polar substance R22.
\end{abstract}

\section{Introduction}

Viscosity of gases, like thermal conductivity and diffusion coefficient, is an important physical property in chemical engineering and in molecular physics. Accurate experimental data of the gas viscosity are used to obtain information about in iermolecular forces and more practically to design unit operations in chemical engineering.

Precise viscosity data of nonpolar gases over a wide range of temperature and pressure have received considerable attention. The viscosity of nonpolar gases increases with increasing pressure and/or density. This behavior can be expressed qualitatively by the Enskog theory ${ }^{6}$ for dense gases. Few investigations of the viscosity of dense gas mixtures containing polar gases has been undertaken. Kestin and Wang ${ }^{21)}$ pointed out that the viscosity of water vapor decreases with an increase in pressure (and/or density) at a particular temperature and the anomalous behavior disappears as the temperature increases. This negative pressure (and/or density) effect on the viscosity was found experimentally for several polar gases, i.e., ammonia, ${ }^{5,11.17 .34)}$ sulfur dioxide ${ }^{18)}$ and hydrocarbon fluorides, ${ }^{15,36-39)}$ and for gas mixtures

\footnotetext{
Received February 4, 1988. Correspondence concerning this article should be ad dressed to $M$. Hongo.
}

containing polar gases, ${ }^{11-13,16.40)}$ in addition to water vapor. $^{20,21,27)}$ While it was found that an empirical correlating viscosity equation for pure gases can represent this negative pressure effect, ${ }^{15,19,33)}$ no equation has been proposed to express the effect of polar gases in gaseous mixtures. Therefore, it is interesting to develop an estimation method which can express the anomalous behavior of viscosity for nonpolarpolar gas mixtures.

In the present study the viscosities of methanechlorodifluoromethane (R22) mixtures have been measured at $298.15,323.15,348.15$ and $373.15 \mathrm{~K}$ up to $5 \mathrm{MPa}$ by a Maxwell type oscillating-disc viscometer. The experimental viscosity values at atmospheric pressure were compared with calculated values from the Chapman and Enskog, ${ }^{10)}$ Wilke $^{41)}$ and Brokaw $^{3,4\}}$ equations. The viscosities of the dense gas mixtures were calculated by two methods. One was the residual viscosity correlation of Dean and Stiel ${ }^{7)}$ with pseudocritical constants determined from the modified Prausnitz and Gunn rule. ${ }^{31)}$ The other was the corresponding states equation of Pedersen and Fredenslund. ${ }^{29.30)}$ We obtained a new empirical equation for a rotational coupling coefficient in order to extend the corresponding states equation to the polar gas R22. 


\section{Experimental}

The viscosities of methane and of methane-R22 gaseous mixtures were measured by a Maxwell type oscillating-disc viscometer. The apparatus and the experimental procedure were the same as those described in detail previously. ${ }^{11,12,15)}$ Measurements of viscosity were carried out at pressures up to $5 \mathrm{MPa}$ and at temperatures of $298.15,323.15,348.15$ and $373.15 \mathrm{~K}$ for methane, up to near the saturated vapor pressure of R22 from 298.15 to $348.15 \mathrm{~K}$, and up to $5 \mathrm{MPa}$ at $373.15 \mathrm{~K}$ for the mixtures. The density of gases required for the viscosity calculation was determined from the Benedict-Webb-Rubin equation of state. ${ }^{11}$ The eight constants in the BWR equation of state for pure gases were obtained from Benedict et $a l .{ }^{1)}$ for methane and from Nohka et al. for R22. ${ }^{28 \text { ? }}$ The mixing rule of Benedict et al. ${ }^{2 y}$ was used for the methane-R22 mixtures.

The methane used in this study was supplied from the Nihon Sanso Co., Ltd. and its purity was $99.95 \%$. The R22 was supplied from the Daikin Kogyo Co., Ltd. and its purity was more than $99.0 \%$. The R22 was purified by redistillation three times. The final purity of the R22 is estimated to be $99.9 \%$. The composition of the mixture employed in this study was determined by use of gas chromatography. The experimental accuracy of the viscosity measurements is estimated to be within $\pm 0.3 \%$.

\section{Experimental Results}

The experimental viscosity values for methane are given in Table 1. To ascertain the reliability of the present viscosity data, the viscosities of methane at atmospheric pressure and those at various other pressures are shown in Figs. 1 and 2, respectively, along with literature values by Hanley et al ${ }^{99}$ denoted by chain lines (the uncertainty: $\pm 2 \%$ ) and by Makita et $a l^{23)}$ denoted by dashed lines (the uncertainty: $\pm 1.5 \%$ ). As can be seen in Fig. 1, the viscosity values obtained in this study agree well with the two other evaluations, and in Fig. 2 the experimental viscosities are located between the two other evaluations at $298.15,323.15$ and $348.15 \mathrm{~K}$, and are in agreement with those evaluations within the range of the respective uncertainties.

The viscosity values for the methane-R22 mixtures are summarized in Table 2 . Figure $\mathbf{3}$ shows the viscosity isotherms of the methane-R22 mixtures at atmospheric pressure. As shown in Fig. 3, the experimental viscosities vary non-linearly with composition and have a maximum at nearly $0.3 \mathrm{~mol}$ fraction of methane at each temperature.

Figure 4 represents the viscosity isotherms of methane-R22 mixtures at $298.15 \mathrm{~K}$ as a function of pressure. The viscosity values of pure $\mathrm{R} 22$ shown in
Table 1. Experimental viscosity values for methane

\begin{tabular}{lcccccc}
\hline $\begin{array}{c}P \\
{[\mathrm{MPa}]}\end{array}$ & $\begin{array}{c}\rho \\
{\left[\mathrm{kg} / \mathrm{m}^{3}\right]}\end{array}$ & $\begin{array}{c}\eta \\
{[\mu \mathrm{Pa} \cdot \mathrm{s}]}\end{array}$ & & $\begin{array}{c}P \\
{[\mathrm{MPa}]}\end{array}$ & $\begin{array}{c}\rho \\
{\left[\mathrm{kg} / \mathrm{m}^{3}\right]}\end{array}$ & $\begin{array}{c}\eta \\
{[\mu \mathrm{Pa} \cdot \mathrm{s}]}\end{array}$ \\
\cline { 1 - 2 } \cline { 6 - 7 } & $298.15 \mathrm{~K}$ & & & 1.973 & 12.09 & 12.23 \\
0.1013 & 0.6569 & 11.18 & & 3.519 & 21.98 & 12.51 \\
0.115 & 0.7425 & 11.19 & & 4.724 & 29.93 & 12.75 \\
0.170 & 1.105 & 11.19 & & $348.15 \mathrm{~K}$ & \\
0.292 & 1.898 & 11.19 & & 0.1013 & 0.5620 & 12.79 \\
0.498 & 3.248 & 11.23 & & 0.523 & 2.914 & 12.83 \\
1.021 & 6.730 & 11.30 & & 1.542 & 8.675 & 12.94 \\
1.506 & 10.01 & 11.33 & & 2.596 & 14.75 & 13.10 \\
2.029 & 13.61 & 11.41 & & 3.580 & 20.52 & 13.27 \\
2.522 & 17.06 & 11.53 & & 4.739 & 27.43 & 13.45 \\
3.001 & 20.48 & 11.59 & & $373.15 \mathrm{~K}$ & \\
3.531 & 24.32 & 11.71 & & 0.1013 & 0.5242 & 13.51 \\
4.024 & 27.95 & 11.82 & & 0.516 & 2.678 & 13.56 \\
4.988 & 35.22 & 12.01 & & 1.010 & 5.261 & 13.58 \\
& $323.15 \mathrm{~K}$ & & & 2.030 & 10.65 & 13.72 \\
0.1013 & 0.6056 & 11.98 & & 2.937 & 15.50 & 13.84 \\
0.524 & 3.150 & 12.03 & & 4.086 & 21.72 & 14.00 \\
0.972 & 5.878 & 12.08 & & 4.943 & 26.40 & 14.14 \\
\hline
\end{tabular}

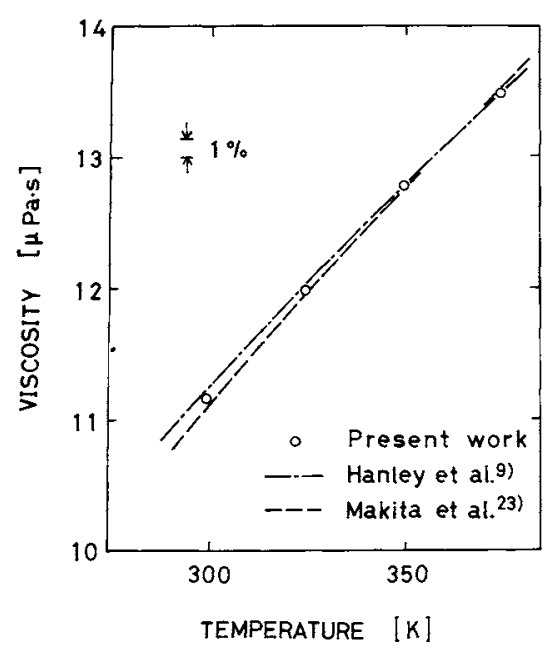

Fig. 1. Experimental viscosity of methane at atmospheric pressure compared with literature values

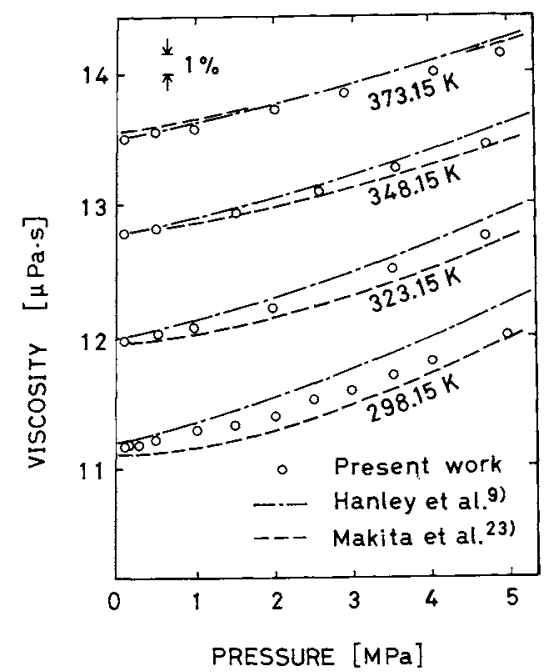

Fig. 2. Experimental viscosity of methane at various pressures compared with .literature values 
Table 2. Experimental viscosity values for methane-R22 mixtures

\begin{tabular}{|c|c|c|c|c|c|}
\hline \multicolumn{3}{|c|}{$298.15 \mathrm{~K}$} & \multicolumn{3}{|c|}{$323.15 \mathrm{~K}$} \\
\hline $\begin{array}{c}P \\
{[\mathrm{MPa}]}\end{array}$ & $\begin{array}{c}\rho \\
{\left[\mathrm{kg} / \mathrm{m}^{3}\right]}\end{array}$ & $\begin{array}{c}\eta \\
{[\mu \mathrm{Pa} \cdot \mathrm{s}]}\end{array}$ & $\begin{array}{c}P \\
{[\mathrm{MPa}]}\end{array}$ & $\begin{array}{c}\rho \\
{\left[\mathrm{kg} / \mathrm{m}^{3}\right]}\end{array}$ & $\begin{array}{c}\eta \\
{[\mu \mathrm{Pa} \cdot \mathrm{s}]}\end{array}$ \\
\hline \multicolumn{3}{|c|}{$x_{\mathrm{CH}_{4}}=0.240$} & \multicolumn{3}{|c|}{$x_{\mathrm{CH}_{4}}=0.237$} \\
\hline 0.1013 & 2.847 & 12.88 & 0.1013 & 2.652 & 13.92 \\
\hline 0.283 & 8.179 & 12.86 & 0.341 & 9.106 & 13.94 \\
\hline 0.499 & 14.79 & 12.83 & 0.742 & 20.52 & 13.98 \\
\hline 0.710 & 21.63 & 12.87 & 1.238 & 35.95 & 14.00 \\
\hline 1.002 & 31.73 & 12.91 & 1.718 & 52.61 & 14.26 \\
\hline \multicolumn{3}{|c|}{$x_{\mathrm{CH}_{4}}=0.510$} & \multicolumn{3}{|c|}{$x_{\mathrm{CH}_{4}}=0.483$} \\
\hline 0.1013 & 2.080 & 12.86 & 0.1013 & 1.988 & 13.90 \\
\hline 0.206 & 4.250 & 12.87 & 0.353 & 7.018 & 13.92 \\
\hline 0.289 & 6.000 & 12.87 & 0.750 & 15.23 & 13.97 \\
\hline 0.496 & 10.46 & 12.89 & 1.305 & 27.35 & 14.07 \\
\hline 0.693 & 14.80 & 12.93 & 1.839 & 39.82 & 14.20 \\
\hline 1.029 & 22.53 & 12.98 & \multicolumn{3}{|c|}{$x_{\mathrm{CH}_{4}}=0.748$} \\
\hline \multicolumn{3}{|c|}{$x_{\mathrm{CH}_{4}}=0.752$} & 0.1013 & 1.278 & 13.52 \\
\hline 0.1013 & 1.375 & 12.43 & 0.354 & 4.496 & 13.56 \\
\hline 0.200 & 2.718 & 12.46 & 0.763 & 9.803 & 13.57 \\
\hline 0.296 & 4.043 & 12.47 & 1.310 & 17.10 & 13.68 \\
\hline 0.500 & 6.878 & 12.50 & 1.863 & 24.72 & 13.78 \\
\hline 0.699 & 9.699 & 12.50 & & & \\
\hline 1.003 & 14.08 & 12.58 & & & \\
\hline \multicolumn{3}{|c|}{$348.15 \mathrm{~K}$} & \multicolumn{3}{|c|}{$373.15 \mathrm{~K}$} \\
\hline $\begin{array}{c}P \\
{[\mathrm{MPa}]}\end{array}$ & $\begin{array}{c}\rho \\
{\left[\mathrm{kg} / \mathrm{m}^{3}\right]}\end{array}$ & $\begin{array}{c}\eta \\
{[\mu \mathrm{Pa} \cdot \mathrm{s}]}\end{array}$ & $\begin{array}{c}P \\
{[\mathrm{MPa}]}\end{array}$ & $\begin{array}{c}\rho \\
{\left[\mathrm{kg} / \mathrm{m}^{3}\right]}\end{array}$ & $\begin{array}{c}\eta \\
{[\mu \mathrm{Pa} \cdot \mathrm{s}]}\end{array}$ \\
\hline \multicolumn{3}{|c|}{$x_{\mathrm{CH}_{4}}=0.290$} & \multicolumn{3}{|c|}{$x_{\mathrm{CH}_{4}}=0.268$} \\
\hline 0.1013 & 2.324 & 14.93 & 0.1013 & 2.217 & 15.94 \\
\hline 0.357 & 8.312 & 14.97 & 0.531 & 11.86 & 16.01 \\
\hline 0.858 & 20.59 & 15.04 & 1.514 & 35.50 & 16.24 \\
\hline 1.539 & 38.61 & 15.20 & 2.533 & 62.84 & 16.64 \\
\hline 2.149 & 56.33 & 15.44 & 3.525 & 92.96 & 17.31 \\
\hline 2.770 & 76.29 & 15.84 & 4.489 & 126.68 & 18.19 \\
\hline \multicolumn{3}{|c|}{$x_{\mathrm{CH}_{4}}=0.492$} & \multicolumn{3}{|c|}{$x_{\mathrm{CH}_{4}}=0.503$} \\
\hline 0.1013 & 1.820 & 14.88 & 0.1013 & 1.671 & 15.88 \\
\hline 0.397 & 7.217 & 14.93 & 0.519 & 8.670 & 15.88 \\
\hline 0.839 & 15.52 & 15.01 & 1.214 & 20.71 & 16.05 \\
\hline 1.438 & 27.27 & 15.12 & 2.403 & 42.56 & 16.37 \\
\hline 2.148 & 42.02 & 15.30 & 3.609 & 66.48 & 16.84 \\
\hline 2.760 & 55.53 & 15.59 & 4.852 & 93.23 & 17.55 \\
\hline \multicolumn{3}{|c|}{$x_{\mathrm{CH}_{4}}=0.777$} & \multicolumn{3}{|c|}{$x_{\mathrm{CH}_{4}}=0.750$} \\
\hline 0.1013 & 1.113 & 14.39 & 0.1013 & 1.100 & 15.39 \\
\hline 0.337 & 3.720 & 14.40 & 0.528 & 5.776 & 15.40 \\
\hline 0.768 & 8.551 & 14.44 & 1.505 & 16.72 & 15.55 \\
\hline 1.466 & 16.55 & 14.57 & 2.518 & 28.44 & 15.75 \\
\hline 2.200 & 25.20 & 14.69 & 3.519 & 40.38 & 16.04 \\
\hline 3.080 & 35.91 & 14.88 & 4.510 & 52.55 & 16.35 \\
\hline
\end{tabular}

this figure were reported previously. ${ }^{15)}$ Figure 4 shows the effect of composition on the isothermal behavior for this system; that is, a negative initial slope of the viscosity isotherm, $(\partial \eta / \partial P)_{T}$, for R22 changes sign as the concentration of methane increases. It is well known, however, that the gas viscosity can be expressed more easily as a function of density than as one of pressure. ${ }^{14)}$ Therefore, Fig. 5 shows the relationship between viscosity and density rather than pressure at the same temperature. Variations in the

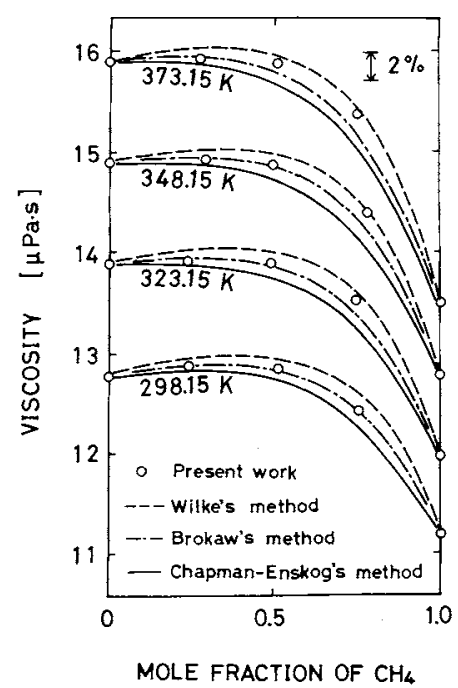

Fig. 3. Viscosity isotherm of methane-R22 mixtures at atmospheric pressure

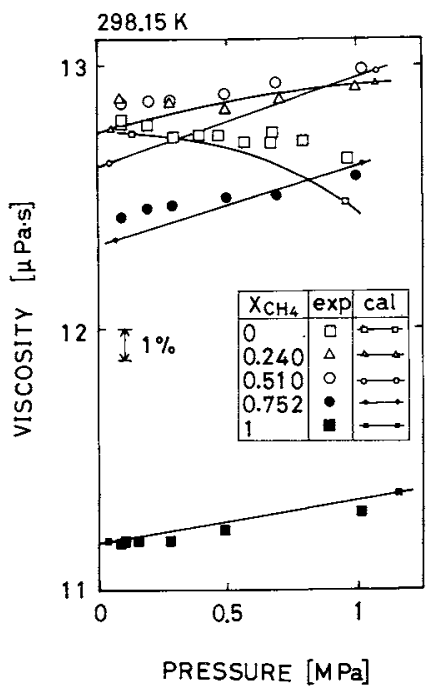

Fig. 4. Viscosity of methane-R22 mixtures at $298.15 \mathrm{~K}$ as a function of pressure

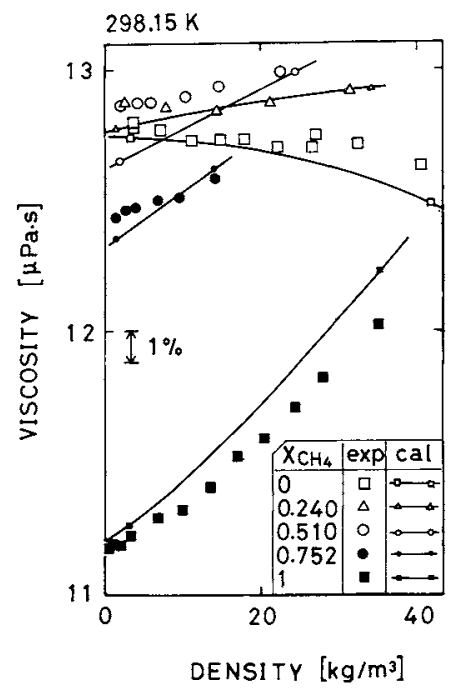

Fig. 5. Viscosity of methane-R 22 mixtures at $298.15 \mathrm{~K}$ as a function of density 
initial slope of the isotherm observed at constant composition can be seen more clearly than those shown in Fig. 4. The same behavior can be seen for the case of the $323.15 \mathrm{~K}$ isotherm, and similar behavior has been reported in the nitrogen-ammonia, ${ }^{11}$ hydrogen-ammonia, ${ }^{12)}$ and argon-ammonia ${ }^{13,16)}$ systems.

\section{Correlation of Gas Viscosity}

\subsection{Viscosity at atmospheric pressure}

1) Chapman-Enskog Equation The viscosity of low-density gas mixtures can be estimated by both theoretical and empirical equations. The equation of viscosity for a binary gas mixture was derived by Chapman and Enskog on the basis of rigorous kinetic theory, and is expressed as follows: ${ }^{8 \text { ? }}$

$$
\eta_{m}^{\circ}=\left(\frac{x_{1}^{2}}{H_{11}^{\circ}}+\frac{x_{2}^{2}}{H_{22}^{\circ}}-\frac{2 x_{1} x_{2} H_{12}^{\circ}}{H_{11}^{\circ} H_{22}^{\circ}}\right) /\left(1-\frac{\left(H_{12}^{\circ}\right)^{2}}{H_{11}^{\circ} H_{22}^{\circ}}\right)
$$

where $x_{i}$ is the mole fraction of component $i$, and

$$
\begin{aligned}
& H_{12}^{\circ}=-\frac{2 x_{1} x_{2}}{\eta_{12}^{\circ}} \frac{M_{1} M_{2}}{\left(M_{1}+M_{2}\right)^{2}}\left(\frac{5}{3 A^{*}}-1\right) \\
& H_{11}^{\circ}=\frac{x_{1}^{2}}{\eta_{11}^{\circ}}+\frac{2 x_{1} x_{2}}{\eta_{12}^{\circ}} \frac{M_{1} M_{2}}{\left(M_{1}+M_{2}\right)^{2}}\left(\frac{5}{3 A^{*}}+\frac{M_{2}}{M_{1}}\right)
\end{aligned}
$$

The expression for $H_{22}^{\circ}$ is obtained from that for $H_{11}^{\circ}$ by interchanging the species subscripts 1 and 2 . The $\eta_{12}^{\circ}$ is the low-density viscosity of a hypothetical pure gas whose molecular mass is $2 M_{1} M_{2} /\left(M_{1}+M_{2}\right)$ and whose molecular interaction is according to the real 1-2 interaction. The $A^{*}$ is a dimensionless ratio of collision integrals and is given by Hirschfelder et al. ${ }^{10)}$ and Monchick et al. ${ }^{25,26)}$

The $\eta_{12}^{\circ}$ is expressed as follows.

$$
\eta_{12}^{\circ}=2.6695 \times 10^{-6} \frac{\sqrt{2 M_{1} M_{2} T\left(M_{1}+M_{2}\right)}}{\sigma_{12}^{2} \Omega_{\eta}\left(T_{12}^{*}\right)}
$$

where $M_{1}$ is a molecular mass of component $1, T_{12}^{*}=$ $k T / \varepsilon_{12}$ is reduced temperature, $\sigma_{12}$ and $\varepsilon_{12}$ are parameters in the potential function characteristic of 1-2 interaction, and $k$ is a Boltzmann constant. When the subscript 2 is replaced by 1 , Eq. (4) expresses the gas viscosity of pure component $1, \eta_{11}^{\circ}$. We used the Lennard-Jones potential for methane-methane interaction, and the Stockmayer potential for R22-R22 interaction.

The Lennard-Jones potential was used for the methane-R22 interaction, whose potential parameters were expressed by the following combining rule. ${ }^{10)}$

$$
\begin{aligned}
& \varepsilon_{12}=\chi^{2}\left(\varepsilon_{11} \varepsilon_{22}\right)^{1 / 2} \\
& \sigma_{12}=(1 / 2) \chi^{-1 / 6}\left(\sigma_{11}+\sigma_{22}\right)
\end{aligned}
$$

in which
Table 3. Potential parameters used in the present study

\begin{tabular}{lccc} 
& $\sigma\left[10^{-10} \mathrm{~m}\right]$ & $\varepsilon / k[\mathrm{~K}]$ & $\delta[-]$ \\
\hline $\mathrm{CH}_{4}$ & 3.692 & 163 & \\
$\mathrm{CHClF}_{2}{ }^{*}$ & 4.711 & 261 & 0.28 \\
\hline
\end{tabular}

* cf. ref. 15 .

$$
\chi=1+(1 / 2) \alpha_{1}^{*} \delta_{2}\left(\varepsilon_{22} / \varepsilon_{11}\right)^{1 / 2}
$$

where $\alpha_{1}^{*}=\alpha_{1} / \sigma_{1}^{3}$ is a reduced polarizability of methane and $\delta_{2}=\mu_{2}^{2} / 2 \varepsilon_{2} \sigma_{2}^{3}$ is the reduced dipole moment of R22. The potential parameters for methane and R22 were determined by fitting the calculated values from Eq. (4) to the experimental data at atmospheric pressure. The potential parameters are listed in Table 3. The calculated results are shown in Fig. 3 by solid lines.

2) Sutherland Equation While various empirical equations for viscosity calculation of gas mixtures have been presented, the most successful was given by Sutherland as follows. ${ }^{35)}$

$$
\eta_{m}^{\circ}=\frac{\eta_{11}^{\circ}}{1+\phi_{12}\left(x_{2} / x_{1}\right)}+\frac{\eta_{22}^{\circ}}{1+\phi_{21}\left(x_{1} / x_{2}\right)}
$$

where $\phi_{12}$ and $\phi_{21}$ are the combination factors.

Wilke ${ }^{41}$ proposed an approximation formula for $\phi_{12}$ and $\phi_{21}$ by using Sutherland's kinetic theory. The $\phi_{12}$ and $\phi_{21}$ are expressed as follows.

$$
\begin{aligned}
& \phi_{12}=\frac{\left[1+\left(\eta_{11}^{\circ} / \eta_{22}^{\circ}\right)^{1 / 2}\left(M_{2} / M_{1}\right)^{1 / 4}\right]^{2}}{\left[8\left(1+M_{1} / M_{2}\right)\right]^{1 / 2}} \\
& \phi_{21}=\left(\eta_{22}^{\circ} / \eta_{11}^{\circ}\right)\left(M_{1} / M_{2}\right) \phi_{12}
\end{aligned}
$$

Brokaw $^{3,4)}$ obtained the following equations for a gas mixture containing polar gas by making an approximation to the rigorous kinetic theory.

$$
\phi_{i j}=\left(\eta_{i i}^{\circ} / \eta_{j j}^{\circ}\right)^{1 / 2} S_{i j} F_{i j}
$$

where

$$
F_{i j}=m_{i j} M_{i j}^{-1 / 2}\left[1+\frac{M_{i j}-M_{i j}^{0.45}}{2\left(1+M_{i j}\right)+\frac{\left(1+M_{i j}^{0.45}\right)}{\left(1+m_{i j}\right)} m_{i j}^{-1 / 2}}\right]
$$

with

$$
\begin{aligned}
m_{i j} & =\left[\frac{4}{\left(1+M_{i j}^{-1}\right)\left(1+M_{i j}\right)}\right]^{0.25} \\
M_{i j} & =M_{i} / M_{j}
\end{aligned}
$$

If the polarity parameter $\delta$ is greater than 0.1 for either component $i$ or $j, S_{i j}$ id defined as

$$
S_{i j}=S_{j i}=\frac{1+\left(T_{i}^{*} T_{j}^{*}\right)^{1 / 2}+\left(\delta_{i} \delta_{j} / 4\right)}{\left[1+T_{i}^{*}+\left(\delta_{i}^{2} / 4\right)\right]^{1 / 2}\left[1+T_{j}^{*}+\left(\delta_{j}^{2} / 4\right)\right]^{1 / 2}}
$$


Table 4. Deviation between experimental and calculated viscosity at atmospheric pressure for $\mathrm{CH}_{4}-\mathrm{R} 22$ system

\begin{tabular}{|c|c|c|c|c|c|c|c|c|c|}
\hline \multirow{3}{*}{$\begin{array}{c}\text { Temp. } \\
{[\mathrm{K}]}\end{array}$} & \multicolumn{9}{|c|}{ Deviation $[\%]^{*}$} \\
\hline & \multicolumn{3}{|c|}{$\begin{array}{l}\text { Chapman-Enskog } \\
\text { (Eqs. (1)-(4)) }\end{array}$} & \multicolumn{3}{|c|}{$\begin{array}{c}\text { Wilke } \\
\text { (Eqs. }(8)-(10) \text { ) }\end{array}$} & \multicolumn{3}{|c|}{$\begin{array}{c}\text { Brokaw } \\
\text { (Eqs. (8) \& (11)) }\end{array}$} \\
\hline & Ave. & Bias & Max. & Ave. & Bias & Max. & Ave. & Bias & Max. \\
\hline 298.15 & 0.34 & 0.34 & 0.55 & 0.76 & -0.76 & 1.35 & 0.16 & 0.10 & 0.31 \\
\hline 323.15 & 0.64 & 0.60 & 1.35 & 0.67 & -0.67 & 0.79 & 0.44 & 0.30 & 0.97 \\
\hline 348.15 & 0.75 & 0.70 & 1.70 & 0.61 & -0.61 & 0.80 & 0.53 & 0.45 & 1.27 \\
\hline 373.15 & 0.80 & 0.72 & 1.58 & 0.50 & -0.50 & 0.56 & 0.65 & 0.61 & 1.38 \\
\hline Total & 0.63 & 0.59 & 1.70 & 0.64 & -0.64 & 1.35 & 0.45 & 0.36 & 1.38 \\
\hline \multicolumn{10}{|c|}{$\begin{array}{l}* \text { Deviation } \\
\quad \text { Ave. }=100 \sum\left\{\left|\eta_{\text {exp }}^{\circ}-\eta_{\text {cal }}^{\circ}\right| / \eta_{\text {cal }}^{\circ}\right\} / n \\
\text { Bias }=100 \sum\left\{\left(\eta_{\text {exp }}^{\circ}-\eta_{\text {cal }}^{\circ}\right) / \eta_{\text {cal }}^{\circ}\right\} / n \\
\text { Max. = maximum of } 100\left\{\left|\eta_{\text {exp }}^{\circ}-\eta_{\text {cal }}^{\circ}\right| / \eta_{\text {cal }}^{\circ}\right\} \\
n=\text { number of data }\end{array}$} \\
\hline
\end{tabular}

where $T_{i}^{*}=k T / \varepsilon_{i}$. If $\delta$ values of both components are less than $0.1, S_{i j}=S_{j i}=1$.

The calculated results from the Wilke equation and the Brokaw equation are shown in Fig. 3 by dashed lines and dot-dash lines, respectively. The deviations between the experimental data and the calculated values are listed in Table 4. It can be seen from Fig. 3 and Table 4 that all three methods give a maximum near 0.3 mole fraction of methane and that Brokaw's equation indicates the best reproducibility.

\subsection{Viscosity of gas mixtures under pressure}

The theoretical equations for dense-gas viscosity were derived on the basis of the kinetic theory and the corresponding states principle. The empirical equation for dense-gas mixture viscosity was developed by Thodos and coworkers. ${ }^{7,19,33)}$ Dean and Stiel ${ }^{7)}$ proposed an empirical viscosity equation for dense-gas mixture as follows.

$$
\begin{aligned}
\left(\eta_{m}-\eta_{m}^{\circ}\right) \xi_{m}= & 0.108\left[\exp \left(1.439 \rho_{r m}\right)\right. \\
& \left.-\exp \left(-1.11 \rho_{r m}^{1.858}\right)\right]
\end{aligned}
$$

where $\eta_{m}$ is dense-gas mixture viscosity, $\eta_{m}^{\circ}$ is dilutegas mixture viscosity, $\rho_{r m}=\rho_{m} / \rho_{c m}$ is pseudoreduced mixture density, $\rho_{m}$ is mixture density, $\rho_{c m}=P_{c m} /$ $\left(Z_{c m} \cdot R \cdot T_{c m}\right)$ is pseudocritical mixture density and $\xi_{m}=T_{c m}^{(1 / 6)} / M_{m}^{(1 / 2)} P_{c m}^{(2 / 3)}$ is a viscosity parameter. The mixture molecular weight $M_{m}$ is a mole fraction average defined by Eq. (22). The pseudocritical mixture parameters, $Z_{c m}, T_{c m}$ and $P_{c m}$, were calculated from the modified Prausnitz and Gunn mixing rule. ${ }^{31)}$

$$
\begin{aligned}
T_{c m} & =\sum_{i} x_{i} T_{c i} \\
Z_{c m} & =\sum_{i} x_{i} Z_{c i} \\
V_{c m} & =\sum_{i} x_{i} V_{c i} \\
P_{c m} & =Z_{c m} \cdot R \cdot T_{c m} / V_{c m}
\end{aligned}
$$

\begin{tabular}{|c|c|c|c|}
\hline \multirow{2}{*}{ Substance } & \multicolumn{3}{|c|}{ Deviation $[\%]^{*}$} \\
\hline & Ave. & Bias & Max. \\
\hline $\mathrm{CH}_{4}$ & 0.37 & -0.37 & 1.31 \\
\hline $\mathrm{R} 22^{+}$ & 3.34 & -3.34 & 6.97 \\
\hline Mixture & 1.21 & -1.21 & 3.75 \\
\hline \multicolumn{4}{|c|}{$\begin{array}{l}\text { * Deviation } \\
\text { Ave. }=100 \sum\left\{\left|\eta_{\text {exp }}-\eta_{\mathrm{ca} 1}\right| / \eta_{\mathrm{ca} 1}\right\} / n \\
\text { Bias }=100 \sum\left\{\left(\eta_{\mathrm{exp}}-\eta_{\mathrm{ca} 1}\right) / \eta_{\mathrm{cal}}\right\} / n \\
\text { Max. = maximum of } 100\left\{\left|\eta_{\mathrm{exp}}-\eta_{\mathrm{ca} 1}\right| / \eta_{\mathrm{ca} 1}\right\} \\
n=\text { number of data }\end{array}$} \\
\hline
\end{tabular}

Table 5. Deviation between experimental data and calculated values from Eq. (16)

The deviation between the experimental data and the calculated values from Eq. (16) is listed in Table 5. It should be noted that the Dean and Stiel equation cannot represent the viscosity decrease of polar gases with increasing density at low temperature.

Pedersen et al. ${ }^{29.30}$ presented a new method for predicting oil and gas mixtures based on the corresponding states principle. The viscosity of a gas mixture at a given pressure $P$ and temperature $T$ is given as follows.

$$
\begin{aligned}
\eta_{m}= & \left(\frac{T_{C M}}{T_{C 0}}\right)^{-1 / 6}\left(\frac{P_{C M}}{P_{C O}}\right)^{2 / 3}\left(\frac{M_{M}}{M_{0}}\right)^{1 / 2} \frac{\alpha_{m}}{\alpha_{0}} \\
& \times \eta_{0}\left[\frac{P \cdot P_{C 0} \cdot \alpha_{0}}{P_{C M} \cdot \alpha_{m}}, \frac{T \cdot T_{C 0} \cdot \alpha_{0}}{T_{C M} \cdot \alpha_{m}}\right]
\end{aligned}
$$

where

$$
=\frac{\sum_{i} \sum_{j} x_{i} x_{j}\left[\left(\frac{T_{C i}}{P_{C i}}\right)^{1 / 3}+\left(\frac{T_{C j}}{P_{C j}}\right)^{1 / 3}\right]^{3}\left(1-k_{i j}\right)\left[T_{C i} T_{C j}\right]^{1 / 2}}{\sum_{i} \sum_{j} x_{i} x_{j}\left[\left(\frac{T_{C i}}{P_{C i}}\right)^{1 / 3}+\left(\frac{T_{C j}}{P_{C j}}\right)^{1 / 3}\right]^{3}}-
$$




$$
P_{C M}=\frac{8 \sum_{i} \sum_{j} x_{i} x_{j}\left[\left(\frac{T_{C i}}{P_{C i}}\right)^{1 / 3}+\left(\frac{T_{C j}}{P_{C j}}\right)^{1 / 3}\right]^{3}\left(1-k_{i j}\right)\left[T_{C i} T_{C j}\right]^{1 / 2}}{\left\{\sum_{i} \sum_{j} x_{i} x_{j}\left[\left(\frac{T_{C i}}{P_{C i}}\right)^{1 / 3}+\left(\frac{T_{C j}}{P_{C j}}\right)^{1 / 3}\right]^{3}\right\}^{2}}
$$

$$
\begin{gathered}
M_{M}=M_{m}+0.291\left(\overline{M_{m}}-M_{m}\right) \\
M_{m}=\sum_{i} x_{i} M_{i} \\
\overline{M_{m}}=\frac{\sum_{i} x_{i} M_{i}^{2}}{\sum_{i} x_{i} M_{i}} \\
\alpha_{m}=1+7.747 \times 10^{-5} \rho_{r}^{4.265} M_{M}^{0.8579} \\
\alpha_{0}=1+8.374 \times 10^{-4} \rho_{r}^{4.265}
\end{gathered}
$$

where $k_{i j}$ in Eqs. (19) and (20) is a binary interaction parameter. The reduced density $\rho_{r}$ is calculated from

$$
\rho_{r}=\frac{\rho_{0}\left(\frac{T \cdot T_{C O}}{T_{C M}}, \frac{P \cdot P_{C O}}{P_{C M}}\right)}{\rho_{C O}}
$$

The subscript 0 indicates the reference substance. The reference substance is methane and the viscosity equation of methane is quoted from Hanley et al. . $^{\text {) }}$ and the equation of state from McCarty. ${ }^{24)}$ The calculated results from Pedersen's equation are listed in Table 6. As can be seen, the error of this equation is comparable to that of the Dean and Stiel equation. The calculated viscosity of R22 from Eq. (18) deviates from the experimental data by about $10 \%$. One of the reasons for this discrepancy may be that the rotational coupling coefficients, Eqs. (24) and (25), are not successful. Pedersen et al. ${ }^{29}$ determined Eqs. (24) and (25) by using viscosity data of hydrocarbons. The $\alpha_{0}$ and $\alpha_{m}$ correspond to the shape factor of the corresponding states principle proposed by Leach $e t$ $a .^{22)}$ Sarashina et $a .^{32)}$ extended the corresponding states principle to systems containing a polar substance. The shape factor determined from the $P V T$ data of ammonia was a rather complicated equation of temperature and density. In this study, we determined the following equation for the ratio of the coupling factors, $\alpha_{m} / \alpha_{0}$, by using the viscosity data for R22

$$
\begin{gathered}
\alpha_{m} / \alpha_{0}=x_{1}+x_{2} \cdot J_{M} \\
J_{M}=a_{0}+a_{1} / T_{r}+\left(a_{2}+a_{3} / T_{r}\right) \rho_{r}
\end{gathered}
$$

where subscript 1 of $x$ is methane and subscript 2 is R22 in Eq. (27), and $T_{r}=T / T_{C M}, \rho_{r}=$ $\rho /\left(P_{C M} /\left(R \cdot T_{C M}\right)\right)$ in Eq. (28). Constants $a_{0}-a_{3}$ in Eq. (28) are as follows:

$$
\begin{array}{ll}
a_{0}=1.00835 & a_{1}=-0.37370 \\
a_{2}=1.50727 & a_{3}=-1.42618
\end{array}
$$

Table 6. Comparison between experimental data and calculated values from Pedersen's original equation and by use of new correlation factor

\begin{tabular}{llrrr}
\hline & & \multicolumn{3}{c}{ Deviation [\% $]^{*}$} \\
\cline { 4 - 5 } & & Ave. & Bias & Max. \\
\hline Original method & $\mathrm{CH}_{4}$ & 0.46 & -0.43 & 1.88 \\
$\begin{array}{l}\text { (Eqs. (18) with } \\
\text { (24) \& (25)) }\end{array}$ & $\mathrm{R} 22$ & 7.37 & -7.37 & 10.23 \\
\hline Mixture & 8.86 & -8.86 & 11.27 \\
This work & $\mathrm{CH}_{4}$ & 0.45 & -0.42 & 1.83 \\
(Eqs. (18) with & $\mathrm{R}_{2}$ & 1.04 & -0.48 & 2.93 \\
$(27))$ & Mixture & 6.97 & -6.97 & 11.43 \\
& $\left(k_{i j}=0\right)$ & & & \\
& Mixture & 0.88 & 0.08 & 3.71 \\
& $\left(k_{i j}=-0.460\right)$ & & & \\
\hline
\end{tabular}

* Definition of deviation is the same as in Table 5.

The results of Eq. (27) are also shown in Table 6, and illustrated in Figs. 4 and 5 by solid lines. It was found that the correlation with the experimental data for the methane-R22 mixtures was improved remarkably by the use of $k_{i j}$ as a fitting parameter.

\section{Conclusion}

To investigate the viscosity of a nonpolar-polar gas mixture under pressure, we measured the viscosity of the methane-R22 system in the temperature range from 298.15 to $373.15 \mathrm{~K}$ and at pressures up to $5 \mathrm{MPa}$.

The viscosity decreased as pressure or density increased in the pressure range from 0.1013 to $0.499 \mathrm{MPa}$ and at $298.15 \mathrm{~K}$ and $x_{\mathrm{CH}_{4}}=0.240$. The same behavior has been observed for some polar gases. Sutherland's equation with Brokaw's combination factor gave the best results for viscosity of the gas mixtures at atmospheric pressure. The residual viscosity correlation of Dean and Stiel with the Gunn and Prausnitz mixing rule was first applied to calculate the viscosity at various pressures. The deviation between experimental and calculated values was typically between -3.4 to $7.0 \%$. The corresponding states correlation of Pedersen et al. was found to give practically the same results for the residual viscosity correlation. We proposed a new empirical correlation factor for a corresponding states correlation that gives improved results for R22. Using the new correlation factor, it was found that the corresponding states correlation could predict the viscosity of methane-R22 system within $3.7 \%$ de- 
viation from the experimental data.

\section{Nomenclature}

$A^{*} \quad=$ collision integral ratio $=\Omega_{\eta} / \Omega_{D}$

$a_{0} \sim a_{3} \quad=$ constants in Eq. (28)

$F_{i j} \quad=$ function of molecular weight defined in Eq. (12)

$J_{M} \quad=$ function defined in Eq. (28)

$k=$ Boltzman constant $\left(1.380622 \times 10^{-23}\right)$

$[\mathbf{J} / \mathbf{K}]$

$=$ binary interaction parameter

$=$ molecular weight

$M_{i j} \quad=$ molecular weight ratio defined in Eq. (14)

$M_{M}=$ mixture molecular weight defined in Eq. (21)

$\overline{M_{m}} \quad=$ weight average molecular weight

$m_{i j} \quad=$ function of molecular weight defined in Eq. (13)

$P \quad=$ pressure

$P_{C M} \quad=$ critical mixture pressure defined in Eq. (20)

$R \quad=$ gas constant $(8.31441) \quad\left[\mathrm{m}^{3} \cdot \mathrm{Pa} /(\mathrm{K} \cdot \mathrm{mol})\right]$

$S_{i j}=S_{j i} \quad=$ function of polarity parameter in Eqs. (11) and (15)

$T \quad=$ temperature

$[-]$

$T_{C M} \quad=$ critical mixture temperature defined in Eq. (19)

$T_{i}^{*} \quad=$ reduced temperature $=k T / \varepsilon_{i}$

$V \quad=$ molar volume

$x \quad=$ mole fraction

$Z \quad=$ compressibility factor

$[\mathrm{K}]$

$=$ polarizability

$=$ coupling factor of reference substance

$=$ coupling factor of mixture

$=$ polarity parameter $=\mu^{2} /\left(2 \varepsilon \sigma^{3}\right)$

$=$ potential parameter

$=$ gas viscosity

$=$ hypothetical gas viscosity defined in Eq. (4)

$=$ dipole moment

$=$ viscosity parameter of gas mixture

$=$ density

$=$ reduced density defined in Eq. (26)

$=$ potential parameter

$=$ combination factor

$=$ constant defined in Eq. (7)

$=$ reduced collision integral

\section{$\langle$ Subscripts〉}

$\begin{array}{ll}1,2, i, j & =\text { molecule } 1,2, i \text { and } j \\ c & =\text { critical property } \\ \text { cal } & =\text { calculated } \\ \mathrm{cm} & =\text { pseudocritical property } \\ D & =\text { diffusion } \\ \exp & =\text { experimental } \\ m & =\text { mixture property } \\ r & =\text { property reduced by critical constant } \\ r m & =\text { pseudoreduced mixture property } \\ \eta & =\text { viscosity } \\ 0 & =\text { reference substance }\end{array}$

$\langle$ Superscripts〉

* $\quad=$ property reduced by potential parameter

= $\quad$ dilute gas property

\section{Literature Cited}

1) Benedict, M., G. B. Webb and L. C. Rubin: J. Chem. Phys., 8 ,

$\left[\mathrm{m}^{3}\right]$

$[-]$

$[-]$

$[-]$

$[\mathrm{J}]$

$[\mathrm{Pa} \cdot \mathrm{s}]$

$[\mathrm{Pa} \cdot \mathrm{s}]$

$[\mathrm{C} \cdot \mathrm{m}]$

$[-]$

$\left[\mathrm{kg} / \mathrm{m}^{3}\right]$

$[-]$

$[\mathrm{m}]$

$[-]$

$[-]$

$[-]$
334 (1940).

2) Benedict, M., G. B. Webb and L. C. Rubin: J. Chem. Phys., 10, 747 (1942).

3) Brokaw, R. S.: J. Chem. Phys., 42, 1140 (1965)

4) Brokaw, R. S.: NASA Tech. Note D-4496 (1968).

5) Carmichael, L. T., H. H. Reamer and B. H. Sage: J. Chem. Eng. Data, 8, 400 (1963).

6) Chapman, S. and T. G. Cowling: "The Mathematical Theory of Non-Uniform Gases," Cambridge Univ. Press, New York (1961).

7) Dean, D. E. and L. I. Stiel: AIChE J., 11, 526 (1965).

8) DiPippo, R., J. R. Dorfman, J. Kestin, H. E. Khalifa and E. A. Mason: Physica, 86A, 205 (1977).

9) Hanley, H. J. M., W. H. Haynes and R. D. McCarty: J. Phys. Chem. Ref. Data, 6, 597 (1977).

10) Hirschfelder, J. O., C. F. Curtiss and R. B. Bird: "Molecular Theory of Gases and Liquids," John Wiley \& Sons, Inc., New York (1964).

11) Hongo, M. and H. Iwasaki: Rev. Phys. Chem. Japan, 47, 90 (1977).

12) Hongo, M. and H. Iwasaki: Rev. Phys. Chem. Japan, 48, 1 (1978).

13) Hongo, M.: Rev. Phys. Chem. Japan, 48, 63 (1978).

14) Hongo, M.: Rev. Phys. Chem. Japan, 49, 1 (1979).

15) Hongo, M. and S. Takahashi: J. Chem. Eng. Japan, 15, 155 (1982).

16) Iwasaki, H., J. Kestin and A. Nagashima: J. Chem. Phys., 40, 2988 (1964).

17) Iwasaki, H. and M. Takahashi: Rev. Phys. Chem. Japan, 38, 18 (1968).

18) Iwasaki, H. and M. Takahashi: Bull. Chem. Soc. Japan, $\mathbf{4 8}$, 988 (1975).

19) Jossi, J. A., L. I. Stiel and G. Thodos: AIChE J., 8, 59 (1962).

20) Kestin, J. and P. D. Richardson: Trans. ASME, 85, 295 (1963).

21) Kestin, J. and H. E. Wang: Physica, 26, 575 (1960)

22) Leach, J. W., P. S. Chappelear and T. W. Leland: AIChE J., 14, 568 (1968).

23) Makita, T., Y. Tanaka and A. Nagashima: Rev. Phys. Chem. Japan, 43, 54 (1973).

24) McCarty, R. D.: Cryogenics, 14, 276 (1974).

25) Monchick, L. and E. A. Mason: J. Chem. Phys., 35, 1676 (1961).

26) Monchick, L., K. S. Yun and E. A. Mason: J. Chem. Phys., 39, 654 (1963).

27) Moszynski, J. R.: Trans. ASME, 83, 111 (1961).

28) Nohka, J., E. Sarashina, Y. Arai and S. Saito: J. Chem. Eng. Japan, 5, 1 (1972).

29) Pedersen, K. C. and Aa. Fredenslund: Chem. Eng. Sci., 42, 182 (1987).

30) Pedersen, K. C., Aa. Fredenslund, P. L. Christensen and P. Thomassen: Chem. Eng. Sci., 39, 1011 (1984).

31) Prausnitz, J. M. and R. D. Gunn: AIChE J., 4, 430 (1958).

32) Sarashina, E., Y. Arai and S. Saito: J. Chem. Eng. Japan, 7, 421 (1974).

33) Stiel, L. I. and G. Thodos: AIChE J., 10, 275 (1964).

34) Summer, B. K. and T. S. Storvick: J. Chem. Eng. Data, 29, 88 (1979).

35) Sutherland, W.: Phil. Mag., 40, 421 (1895).

36) Takahashi, M., S. Takahashi and H. Iwasaki: Kagaku Kogaku Ronbunshu, 9, 482 (1983).

37) Takahashi, M., S. Takahashi and H. Iwasaki: Kagaku Kogaku Ronbunshu, 10, 7 (1984).

38) Takahashi, M., C. Yokoyama and S. Takahashi: Kagaku Kogaku Ronbunshu; 11, 155 (1985).

39) Takahashi, M., C. Yokoyama and S. Takahashi: J. Chem. 


\title{
FLOW STRUCTURE AND MIXING MECHANISM IN AN AGITATED THIN-FILM EVAPORATOR
}

\author{
SATORU KOMORI, KAZUTAKA TAKATA AND YASUHIRO MURAKAMI \\ Department of Chemical Engineering, Kyushu University, Fukuoka 812
}

\author{
Key Words: Fluid Mechanics, Agitation, Evaporator, Thin-Film Flow, Mixing
}

\begin{abstract}
The flow structure and mixing mechanism of the high-viscosity fluid in an agitated thin-film evaporator were experimentally and numerically investigated. Film thickness, holdup and power consumption were measured, and velocity distributions were numerically calculated using a finite element method. The results show that most of the fluid flows down in a fillet and that mixing between fillet and film is extremely suppressed. This also suggests that usual thin-film evaporators are not always effective.
\end{abstract}

\section{Introduction}

Agitated thin-film evaporators are widely used to concentrate polymer solutions by evaporating solvents in industrial processes. The evaporator can be operated in a vacuum, and the residence time of a solution in the equipment can be reduced to less than a few seconds. The agitated thin-film evaporator can therefore find wide application in food, pharmaceutical and petrochemical processes which involve the operations of refining, concentration or deodorization. In such processes the solutions are often prone to thermal decomposition, or have the high viscosity or low thermal conductivity, making the thin-film evaporator even more useful. The evaporator equipment and its application are described in detail by Leonald ${ }^{3)}$ and Mutzenburg et al. ${ }^{5 \text { ) }}$

An agitated thin-film evaporator with a rotor blade is sketched in Fig. 1. The supplied fluid flows down along the vertical cylindrical shell-wall and is agitated by a rotor blade. A clearance is held as a gap between the fixed blade-tip and the cylindrical wall. The agitation by the blade forms a film falling along the cylindrical wall and a falling fillet in the periphery of the blade. The falling film consists of both a radial drag flow due to the rotor blade and a downward flow due to gravity. The fillet consists of a falling spiral flow. These flow configurations suggest that the film flow may contribute both to heat transfer between the

\footnotetext{
Received February 19, 1988. Correspondence concerning this article should be
} addressed to S. Komori. fluid and the cylindrical wall and evaporation through the film surface, and that the fillet flow may predominate in momentum and mass transfer between the film and the fillet. Thus, it is of great importance to investigate the flow structure and mixing mechanism in the film and fillet flows in designing an effective thin-film evaporator.

Kern and Karakas ${ }^{2)}$ and Godau ${ }^{1)}$ analytically calculated the film thickness and falling velocity of highviscosity fluid in the thin-film evaporator under isothermal conditions without evaporation. Their analyses were based on the equations of motion. However, they neither compared the predictions with the measurements nor analyzed the flow structure in the fillet. Nakamura and Watanabe ${ }^{6)}$ investigated the low-viscosity flow in an agitated thin-film evaporator under isothermal operating conditions. They approximately estimated the fillet size on the $(r, \theta)$-plane and calculated the liquid holdup by means of a

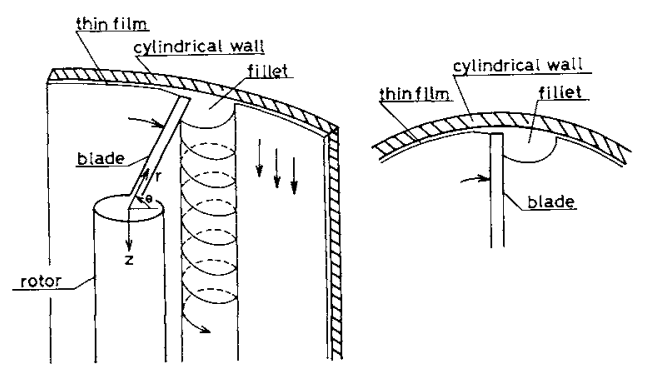

Fig. 1. Schematic diagram of an agitated thin-film evaporator and flow field 